\title{
INGLÊS INSTRUMENTAL E A EXPERTISE COMPARTILHADA: CONVERGÊNCIAS COM A TRADUÇÃO E A TERMINOLOGIA
}

\author{
Silvia Helena Benchimol Barros 1 \\ 1 Universidade Federal do Pará, Belém, Pará, Brasil
}

\begin{abstract}
Resumo: Este artigo aborda criticamente aspectos pertinentes ao ensino da língua inglesa em textos de especialidade na dimensão do Ensino Instrumental, problematiza essa abordagem considerando o contexto dos cursos livres de idioma - com foco na competência de leitura - em modalidade EAP ${ }^{1}$ (STREVENS, 1977; HYLAND, 2006) e estabelece convergências teóricas com os campos da Tradução e Terminologia. A perspectiva adotada visa contribuir com o desempenho dos agentes envolvidos e com o aprimoramento da prática pedagógica, expandindo novos caminhos e possibilidades teórico-metodológicas. A motivação para este estudo emerge da crescente e expressiva procura pelo desenvolvimento da competência de leitura em textos com conteúdo científico em língua estrangeira por profissionais e acadêmicos de áreas diversas. Esta demanda caracteriza-se por metas bem definidas em seus domínios de atuação associadas à busca por mecanismos de aceleração de resultados decorrente da pressão exógena por qualificação. Pretende-se descrever as peculiaridades do contexto de ensino de onde partem estas reflexões e relacionar alguns mecanismos utilizados metodologicamente no processo de resolução de dificuldades exploratórias do texto com estratégias tradutórias e conhecimentos de cunho terminológico.
\end{abstract}

Palavras-chave: Ensino instrumental; Cursos livres de idiomas; Tradução; Terminologia; Expertise compartilhada.

${ }^{1}$ English for Academic Purposes. 


\title{
ESP AND THE SHARED EXPERTISE: CONVERGENCES WITH TRANSLATION AND TERMINOLOGY
}

\begin{abstract}
This paper critically addresses aspects related to the teaching of the English language in specialized texts in the scope of English for Specific Purposes. It problematizes this approach within the context of language courses - focusing on the reading competence - EAP modality (STREVENS, 1977; HYLAND, 2006). It establishes theoretical convergences with the fields of Translation and Terminology. The perspective adopted aims to contribute to the development of the agents involved and to the improvement of pedagogical practice, broadening new paths and theoreticalmethodological possibilities. The motivation for this study emerges from the growing and expressive pursuit of reading competence enhancement in texts with scientific content in foreign languages by professionals and academics from different domains. This demand is characterized by well-defined professional targets associated to mechanisms of acceleration of results stemming from the exogenous pressure for qualification. It is intended to describe the peculiarities of the teaching context where these reflections emerge from and connect them to some methodological procedures employed in solving textual exploratory difficulties supported by translation strategies and terminological knowledge.
\end{abstract}

Keywords: ESP teaching; Language courses; Translation; Terminology; Shared expertise.

\section{Introdução}

Muito se tem produzido e discutido a respeito do Inglês Instrumental (II) na perspectiva linguística e dos gêneros textuais (HUTCHINSON \& WATERS, 1987; HYLAND, 2002, 2004). Entretanto, pouco espaço galgou-se na literatura nacional, sobre a convergência entre as estratégias de tradução e os conhecimentos terminológicos que subjazem esta disciplina. Este artigo focaliza o texto fonte em língua inglesa, o discurso científico e áreas de especialidade distribuídas em largo espectro de possibilidades.

Metodologicamente, o estudo se propõe a traçar as interfaces teóricas previamente referidas, analisar excertos extraídos de al- 
guns textos utilizados como práticas nas aulas de Inglês Instrumental dos Cursos Livres da Universidade Federal do Pará e, a partir deles, identificar a inevitabilidade da expertise compartilhada como estratégia de ensino. Os recortes que constituem o corpus apontam para a necessidade de alcançar sentidos a partir de mecanismos tradutórios, dada a presença de unidades terminológicas de diferentes densidades, as quais não compõem o léxico dos dicionários gerais da língua, dos quais geralmente se utilizam estes alunos. São também trazidas as evidencias da competência bilíngue como componente essencial ao processo interpretativo do discurso acadêmico-científico.

Pretende-se que os resultados destas reflexões possam servir de subsídios para discussão e implementação de currículos de cursos de língua estrangeira Instrumental e das competências docentes, via expansão do plano de contato entre ensino de língua estrangeira, tradução e terminologia e, assim, resgatar um vínculo fragilizado historicamente no cenário do ensino-aprendizagem de línguas.

\section{Contextos particularizados e implicações didático- metodológicas}

É tácita a compreensão de que o aspirante ao curso de Inglês Instrumental não é o típico aluno que busca a aprendizagem do idioma estrangeiro com vistas a desenvolver as quatro habilidades da língua nos níveis de compreensão e produção com integração e equilíbrio equitativo. Ao contrário disso, o potencial aluno de Inglês Instrumental é movido por uma necessidade específica, bem delimitada que não tem como fim o conhecimento da língua estrangeira per se, e sim o de utilizá-lo como ferramenta para chegar algures, seja por meio das habilidades de escuta, fala, leitura ou escrita. 
Cabe, a priori, rever alguns aspectos convergentes do Inglês para Fins Específicos (ESP) ${ }^{2}$ e do Inglês para Fins Acadêmicos $(E A P)^{3}$ conforme argumenta Strevens (1977). Segundo o autor, ambas as modalidades aproximam-se por balizarem o ensino da língua pelos propósitos imediatos dos aprendizes; por selecionarem do universo geral da língua, apenas os itens lexicais, gramaticais, funcionais-linguísticos que são exigidos por estes propósitos; por incluírem apenas tópicos, temas e contextos discursivos que são diretamente relevantes às necessidades prementes dos mesmos; e por abordarem somente as demandas comunicativas que se relacionam com os seus interesses. Apesar das significativas afinidades entre EAP e ESP, este último não se restringe à um único contexto e abraça uma variedade de gêneros discursivos bem mais ampla (ASKEHAVE \& SWALES, 2001; BELCHER, 2006, 2009; BHATIA, 1993; JOHNS \& DUDLEY-EVANS, 1991; PALTRIDGE, 2013; SWALES, 1990).

Hamp-Lyons (2001, p.127) refere que as delimitações e enquadramentos imediatistas que se constituíram como particularidades do ESP e que têm como fundamento os interesses dos aprendizes resultaram em insatisfações com relação às suas abordagens iniciais. Contrariamente, o EAP não foi alvo das mesmas críticas pelo fato de o contexto acadêmico ter se provado suficientemente rico e relevante em conteúdos específicos que satisfizessem as demandas dos interessados e, em analogia, suficientemente gerais para aplicação em uma razoável amplitude de contextos. As três dimensões destacadas pela autora como essenciais ao EAP e que devem refletir dados provenientes da direcionadora "análise de necessidades", são:

${ }^{2}$ Acrônimo em língua inglesa comumente utilizado na literatura da área e que designa English for Specific Purposes. Há ocorrências em artigos nacionais da sigla ELFE - Ensino de línguas para fins específicos.

3 Acrônimo em língua inglesa comumente utilizado na literatura da área e que designa English for Academic Purposes. Há ocorrências nacionais da sigla IFA Inglês para fins acadêmicos. 
- Registro: especificidades lexicais e gramaticais

- Discurso: efeito do contexto comunicativo; relação entre texto-discurso e seus agentes enunciadores/escritores/ouvintes/leitores.

- Gênero: como a língua é utilizada em situações particulares, tais como artigos de pesquisas, dissertações, palestras formais.

Estudos revelam que a denominação Inglês Instrumental (ESP) tem sido aplicada à situações de ensino com objetos, objetivos, ambiências, e público-alvo bem distintos e aglutinam em seus escopos muitas variedades como EAP, EOP, EBP, ELP, EMP ${ }^{4}$, outros. O Quadro (1) abaixo sintetiza os mais frequentes cenários observados no Brasil e estruturou-se a partir de minha constatação pessoal sobre a dinâmica de estruturação das turmas de ensino de Inglês Instrumental para os diversos cursos de nível superior da UFPA, com subsídio em ementários de diversas IES brasileiras disponíveis online e estudos complementares publicados sobre o tema (ARAÚJO, 2015; CELANI, 1983, 2005; RAMOS, 2009).

Quadro 1 - Frequentes cenários de Inglês Instrumental no Brasil

\begin{tabular}{|c|c|c|c|}
\hline $\begin{array}{l}\text { Contexto } \\
\text { de ensino }\end{array}$ & $\begin{array}{l}\text { Objeto } \\
\text { (tipo de texto) }\end{array}$ & Objetivo & Público-alvo \\
\hline $\begin{array}{l}\text { (1) } \\
\text { Ensino } \\
\text { superior } \\
\text { Licenciaturas } \\
\text { em línguas } \\
\text { estrangeiras }\end{array}$ & $\begin{array}{l}\text { Especialidade; } \\
\text { língua inglesa; } \\
\text { temas da área } \\
\text { de linguagens. } \\
\text { Abordagem } \\
\text { monolíngue }\end{array}$ & $\begin{array}{l}\text { Apropriação do } \\
\text { discurso profissional } \\
\text { e sua terminologia. } \\
\text { Viabilização da } \\
\text { interação entre } \\
\text { especialistas. } \\
\text { Aprimoramento } \\
\text { e alinhamento do } \\
\text { discurso }\end{array}$ & $\begin{array}{l}\text { Acadêmicos, } \\
\text { futuros } \\
\text { profissionais da } \\
\text { área da linguagem, } \\
\text { com domínio da } \\
\text { língua inglesa }\end{array}$ \\
\hline
\end{tabular}

${ }^{4}$ Dudley-Evans \& St. John (1998); Hutchinson \& Waters (1987) apresentam uma variedade de modalidades de ESP. Entre as mais gerais estão: EAP (English for Academic Purposes); EOP (English for Occupational Purposes); EBP (English for Business Purposes); ELP ( English for Legal Purposes); EMP ( English for Medical Purposes). 


\begin{tabular}{|c|c|c|c|}
\hline $\begin{array}{l}(2) \\
\text { Ensino } \\
\text { superior } \\
\text { Outras } \\
\text { Licenciaturas } \\
\text { e } \\
\text { bacharelados }\end{array}$ & $\begin{array}{l}\text { Especialidade; } \\
\text { língua inglesa; } \\
\text { temas de } \\
\text { diferentes áreas } \\
\text { do conhecimento. } \\
\text { Abordagem } \\
\text { bilíngue }\end{array}$ & \begin{tabular}{|l|} 
Aquisição de \\
competências de \\
leitura em língua \\
inglesa para fins \\
acadêmicos e \\
profissionais. \\
Otimização do acesso \\
à informação da área \\
científica de interesse
\end{tabular} & $\begin{array}{l}\text { Acadêmicos, } \\
\text { futuros } \\
\text { profissionais que } \\
\text { compartilham } \\
\text { uma mesma área } \\
\text { do conhecimento; } \\
\text { competências } \\
\text { limitadas em língua } \\
\text { inglesa. }\end{array}$ \\
\hline $\begin{array}{l}\text { (3) } \\
\text { Cursos Livres } \\
\text { de Idiomas }\end{array}$ & $\begin{array}{l}\text { Gerais; diversos } \\
\text { gêneros e } \\
\text { discursos; } \\
\text { língua inglesa. } \\
\text { Abordagem } \\
\text { bilíngue. }\end{array}$ & $\begin{array}{l}\text { Aquisição de } \\
\text { competências de } \\
\text { leitura em língua } \\
\text { inglesa. Otimização } \\
\text { da percepção } \\
\text { textual em diversos } \\
\text { contextos de uso }\end{array}$ & \begin{tabular}{|l|} 
Alunos de \\
diversos níveis \\
de ensino, áreas \\
do conhecimento \\
e interesses; \\
competências \\
limitadas em língua \\
inglesa.
\end{tabular} \\
\hline $\begin{array}{l}\text { (4) } \\
\text { Cursos Livres } \\
\text { de Idiomas }\end{array}$ & $\begin{array}{l}\text { Especialidade; } \\
\text { língua inglesa; } \\
\text { temas de } \\
\text { diferentes áreas } \\
\text { do conhecimento. } \\
\text { Abordagem } \\
\text { bilíngue }\end{array}$ & $\begin{array}{l}\text { Aquisição da } \\
\text { competência de } \\
\text { leitura em língua } \\
\text { inglesa para fins } \\
\text { acadêmicos e } \\
\text { profissionais. } \\
\text { Otimização do acesso } \\
\text { à informação da área } \\
\text { científica de interesse }\end{array}$ & $\begin{array}{l}\text { Acadêmicos, } \\
\text { futuros } \\
\text { profissionais de } \\
\text { diversas áreas do } \\
\text { conhecimento; } \\
\text { interesses } \\
\text { acadêmicos e } \\
\text { profissionais } \\
\text { distintos; } \\
\text { competências } \\
\text { limitadas em língua } \\
\text { inglesa }\end{array}$ \\
\hline
\end{tabular}

Fonte: Elaborado pela autora com subsídios em fluxogramas e ementários de IES brasileiras disponibilizados online e artigos correlatos.

Percebe-se por este mapeamento baseado em dados empíricos, que embora compartilhando a mesma denominação, as especificidades da disciplina têm implicações didático-metodológicas distintas em função das variáveis: contexto, objeto, objetivo e público-alvo. Isto implica em ênfases diferenciadas dos processos tradutórios e terminológicos; identificação de gêneros textuais e utilização de língua materna ou estrangeira. 
O que designo e trato como Inglês Instrumental neste artigo corresponde ao quarto cenário descrito. Trato da singularidade do ensino desta modalidade em cursos livres de idiomas, nos quais se visa otimizar a compreensão de textos de um determinado gênero linguístico e discursivo. É precisamente deste contexto que emergem minhas reflexões: um público-alvo representativamente constituído por profissionais e acadêmicos em vias de submissão a processos seletivos para os cursos de pós-graduações estrito senso, ou com demandas acadêmicas e de mercado que lhes impõe a necessidade de leitura e apreensão do conteúdo do texto de especialidade em língua estrangeira.

\section{O papel do mediador diante do aprendiz especialista no cenário de compartilhamento}

O docente que media o desenvolvimento das competências de leitura em turmas de Inglês Instrumental tem claro que sua função está condicionada aos propósitos previamente estabelecidos pelas necessidades expressas dos alunos (needs assessment) e à um currículo de curso centrado, via de regra, nos aspectos linguísticos (lexicais e sintáticos) e estratégias de abordagem textual com objetivos de curto prazo. Seu desafio é otimizar os níveis de compreensão a serem alcançados por aprendizes que não raro, possuem conhecimentos bem reduzidos da língua estrangeira. Esse docente é, portanto, um profissional com desenvolvida competência bilíngue e com destacadas habilidades didático-pedagógicas de natureza analítica. Ainda que o texto de especialidade tenha sua função comunicativa inconteste, a finalidade primeira, nesta circunstância, não é sócio interativa mas a de propiciar uma relação do leitor com o conteúdo textual, que demanda substancial utilização de metalinguagem para o trato e explicitação dedutiva das questões lexicais, sintáticas, discursivas e terminológicas manifestas no texto.

Materializa-se aqui, um encontro de dois especialistas de campos distintos do conhecimento - o que domina o saber sobre a 
língua e o que domina o saber sobre o conteúdo de especialidade - situação esta, em que o saber de um e o de outro sobrepõem-se alternadamente criando uma situação de hierarquia compartilhada e complementar, indispensável aos resultados efetivos do processo de ensino-aprendizagem. Decorre deste compartilhamento de expertise a dissociação do ato de ensinar da figura do professor e a transferência de foco para o polo do aprendiz não apenas pelo fato de serem estes, priorizados pelo método em si e seus propósitos direcionarem a seleção de estratégias e conteúdos, mas pela própria necessidade de compartilhamento do saber sobre o objeto de aprendizagem - o texto de especialidade ( léxico especializado) e o controle que assumem em determinadas situações.

$\mathrm{O}$ docente por deter o conhecimento das línguas estrangeira e materna nos seus níveis lexicais, formais, textuais e discursivos exerce um domínio relativo sobre o texto e sobre as interações co-textuais dos elementos linguísticos, o que, no entanto, não lhe assegura a compreensão das camadas conceituais subjacentes e expressas pela terminologia específica. Coloca-se acessível ao docente, uma percepção limitada dos sentidos do texto que lhe possibilita a reprodução do que é dito e representado pelos signos linguísticos manipulados pelo autor na dimensão do co-texto, sem contudo alcançar a penetração substancial do conteúdo de especialidade ali presente, e que concerne ao especialista da área científica. $\mathrm{Na}$ busca pela apropriação dos sentidos, docente e aluno, seguem trajetórias semasiológicas e onomasiológicas, respectivamente, para a resolução de problemas de compreensão lexical - textual. Esta realidade singular pode esclarecer o fato de alguns testes de proficiência de leitura, elaborados por linguistas, serem demasiadamente objetivos e até óbvios em seus questionamentos, pois estão a testar "língua", tão somente, e não o conhecimento do conteúdo das camadas menos superficiais.

Por outro lado, o aluno especialista a quem falta o conhecimento da língua estrangeira, mas hipoteticamente detém do conhecimento teórico-conceitual, está propenso às extrapolações em suas respostas, a lançar mão da informação das entrelinhas e utilizar 
esta mais valia para equilibrar suas limitações na leitura como estratégia compensatória. Sua interação com o texto é de natureza diferente daquela do professor de língua. $\mathrm{O}$ aluno neste caso é um leitor a quem o texto comunica muito mais. Situações problemáticas e discutíveis na aferição de resoluções de questões podem advir deste desalinho.

Coexistem ainda neste cenário, um contexto de situação que liga o texto à situação de produção - uma ambiência de coerência de registro e gênero - que, nesta situação, enredam o aluno-leitor, os signos linguísticos, o tema, o autor do texto e a comunidade científica por meio de suas metafunções em perspectiva tridimensional e; um “cenário situacional material” (HASAN, 1996, p. 36) que envolve interação verbal de natureza sóciocomunicativa entre os agentes docente e alunos. Este cenário é responsável pela orquestração das relações de ensino sem interferir nos sentidos do texto.

O compartilhamento do saber, onde a hierarquia e a mediação se alternam nos polos docente-discente, eu reputo como bastante significativa na interação do processo de ensino-aprendizagem e pode-se dizer que resulta em um dos polos, da limitação de cunho terminológico da dimensão conceitual do léxico de especialidade e de outro, da carência de conhecimentos linguísticos e discursivos na língua estrangeira. Reiterando que as turmas de Inglês Instrumental no cenário apontado agrupam alunos de variadas áreas de interesse, estas constatações apontam para a necessidade de reflexão sobre estratégias de ensino que comportem tal diversificação e o desenvolvimento de metodologias mais eficazes e mais comprometidas com a leitura efetiva dos textos de especialidade como as que direcionam as buscas por correspondentes ou equivalentes lexicais, as de cunho colaborativo que envolvem as construções coletivas de glossários terminológicos bilíngues, agrupamento de alunos-leitores por áreas, levantamento e compartilhamento de glossários existentes online, fóruns de discussão e resolução colaborativa de questões interpretativas, e pesquisa de textos paralelos (GAVIOLI, 2005) para construção de corpora de especialidade. 
Sustentam também as especificidades desse cenário material, os princípios Andragógicos de "auto-direcionamento dos aprendizes" e as relações preestabelecidas nos "contratos de aprendizagem" (DeAQUINO, 2007; HENSCHKE, 2008; KNOWLES, 1980). DeAquino (ibidem, p. 12) sintetiza as características da Andragogia no Quadro (2) abaixo.

\section{Quadro 2 - Contraste Pedagogia x Adragogia}

\begin{tabular}{|c|c|}
\hline $\begin{array}{l}\text { Pedagogia } \\
\text { (aprendizagem centrada no professor) }\end{array}$ & $\begin{array}{c}\text { Andragogia } \\
\text { (aprendizagem centrada no aprendiz) }\end{array}$ \\
\hline Os aprendizes são dependentes & $\begin{array}{c}\text { Os aprendizes são independentes e } \\
\text { autodirecionados }\end{array}$ \\
\hline $\begin{array}{l}\text { Os aprendizes são motivados de forma } \\
\text { extrínseca (recompensas, competiçâa } \\
\text { etc.) }\end{array}$ & $\begin{array}{c}\text { Os aprendizes são motivados de forma } \\
\text { intrínseca (satisfação gerada pelo } \\
\text { aprendizado) }\end{array}$ \\
\hline $\begin{array}{c}\text { A aprendizagem é caracterizada por } \\
\text { técnicas de transmissão de } \\
\text { conhecimento (aulas, leituras } \\
\text { designadas) }\end{array}$ & $\begin{array}{l}\text { A aprendizagem é caracteriza por } \\
\text { projetos inquisitivos, experimentação e } \\
\text { estudo independente. }\end{array}$ \\
\hline $\begin{array}{l}\text { O ambiente de aprendizagem é formal } \\
\text { e caracterizado pela competitividade e } \\
\text { por julgamento de valor. }\end{array}$ & $\begin{array}{l}\text { O ambiente de aprendizagem é mais } \\
\text { informal e caracterizado pela equidade, } \\
\text { respeito mútuo e cooperação. }\end{array}$ \\
\hline $\begin{array}{l}\text { O planejamento e a avaliação săo } \\
\text { conduzidos pelo professor. }\end{array}$ & $\begin{array}{l}\text { A aprendizagem pressupóe ser } \\
\text { baseada em experiências. }\end{array}$ \\
\hline $\begin{array}{l}\text { A avaliação é realizada basicamente } \\
\text { por meio de métodos externos (notas } \\
\text { de testes e provas) }\end{array}$ & $\begin{array}{l}\text { As pessoas säo centradas no } \\
\text { desempenho de seus processos de } \\
\text { aprendizagem. }\end{array}$ \\
\hline
\end{tabular}

Fonte: DeAquino (2007, p.12)

As peculiaridades circunstanciais apontadas no quarto cenário, impulsionam o docente tanto para uma prática de empoderamento do aluno, o qual precisa sentir-se efetivamente participativo, por meio da recognição de seu conhecimento prévio na área de seu interesse, quanto para o desempenho de explicações analíticas e consistentes ao nível linguístico, que legitimem o saber docente nesta situação de compatibilização de expertise. Refiro-me à explicitude do insumo tal como proposta por Schmidt $(1990)^{5}$, isto é, a clareza

${ }^{5}$ A Noticing Hypothesis (Schmidt) propõe que o insumo linguístico não se torna assimilável na aprendizagem de línguas a menos que seja percebido, isto é, conscientemente (Schmidt, 1990, 2001). 
das análises que trazem ao nível consciente da cognição os pontos nodais do texto em questão - language awareness.

Essas questões substanciam a proposta de uma atuação socioconstrutivista de docentes e discentes com envolvimento ativo em experiências autênticas de aprendizagem (KIRALY, 2000) na leitura, nas negociações de sentidos e nas interpretações que vão além da utilização dos dicionários, que no entanto, têm sua função categórica no processo exploratório.

\section{Psicolinguística e Instrumentos lexicográficos e terminográficos de suporte}

A forma pela qual a língua se estrutura nos textos de especialidade produz implicações tanto em sua compreensão - sua pré-tradução - entendida como processo psicolinguístico durante a leitura, quanto nas estratégias de ensino a serem adotadas para sua abordagem. Constata-se, tacitamente, que decorrem na leitura os movimentos de compreensão - em língua estrangeira na busca por informação, e produção na organização dos sentidos e resolução dos problemas de interpretação redacionados em língua materna, conforme são geralmente convencionadas as atividades e os exames de proficiência de leitura em língua estrangeira.

Como descrição de um processo tradutório psicolinguístico, Bell (1998, p. 187) explicita

[Um] modelo do processo tradutório, portanto, reproduz inevitavelmente todas as características de um modelo geral de comunicação humana, acrescentando-lhe alguns componentes inerentes à tradução, especialmente aqueles que representam o reconhecimento do problema e as estratégias empregadas em sua solução. ${ }^{6}$

${ }^{6}$ Nossa tradução para o original: “[a] model of the translation process, then, inevitably replicates all the characteristics of a general model of human 
Ressalto que, apesar de termos em questão um leitor que não detém a competência bilíngue (PACTE, 2005) em equilíbrio nos polos língua estrangeira - língua materna, concretizam-se durante a sua atividade exploratória do texto, as estratégias psicolinguísticas de seleção, antecipação, inferência e verificação (BRASIL, 1998, p. 70) para atingir os propósitos imediatos de uma leitura que tem à frente a solução de questionamentos que exigem interpretação, tradução de sentidos e por vezes a transcrição de trechos para a língua materna. Os elementos básicos do processo psicolinguístico estão presentes na demanda que lhe é imposta, exigindo assim, competências outras que o habilitem para o objetivo específico da leitura, potencializem estratégias de localização e processamento da informação e a capacidade de redacionar o texto conclusivo em sua língua materna.

Esta é outra especificidade do ensino instrumental, ou seja, a mais valia do conhecimento da área de especialidade subsidia a qualidade da produção textual em língua materna. No enfoque do texto de especialidade, lidamos simultaneamente com as estratégias de processamento da informação nos sentidos descendente e ascendente de onde derivam as já bem convencionadas estratégias de skimming e scanning, respectivamente. Ora prevalece o contexto maior extralinguístico e envolvente - o contexto de situação - ora as relações entre as unidades mais discretas do texto, de onde emerge a unidade lexical - o termo. Faulstich afirma que "o significado se serve de uma gramática no processo de formulação do conceito que prepara o termo para receber a definição" (FAULSTICH e ABREU, 2003, p. 12). De forma similar, percebe-se que a gramática se coloca a serviço da constituição dos gêneros textuais e discursivos de especialidade para a transmissão dos sentidos presentes nos termos. Isto é, a língua modela-se para receber o termo.

Partindo-se desta ótica funcional da gramática e da terminologia e da superação das concepções Wusterianas de univocidade e monor-

communication, with the addition of some components which are translationspecific, particularly components which represent problem-recognition and the strategies employed for problem-solving." 
referencialidade do termo, substancia-se a importância da compreensão do contexto do texto onde o termo se manifesta. O conhecimento do contexto de situação é via fundamental para eliminar os desvios interpretativos decorrentes da presença de vocábulos desconhecidos e polissêmicos; e de termos e unidades fraseológicas em língua estrangeira que podem igualmente apresentar variações resultantes de opções conscientes do autor, de processos culturais ou diacrônicos.

Portanto, além dos conhecimentos basilares da estrutura composicional textual com que se manifesta o gênero artigo científico, há que se considerar sua função de comunicar e intercambiar resultados de pesquisas com precisão e fidedignidade. Para esta tarefa revela-se indispensável a utilização de instrumentos de suporte e mecanismos de consulta para auxílio nas atividades leitora e tradutora. $\mathrm{Na}$ impraticabilidade de um instrumento lexicográfico bilíngue que abranja o patrimônio universal de uma língua ou de instrumentos terminológicos que incorporem a terminologia de todas as áreas de especialidade, os dicionários preferencialmente utilizados e indicados aos alunos são os dicionários de léxico geral.

A este respeito refere Biderman (2006)

(...) a expansão do universo cognoscível na contemporaneidade em virtude da ampliação ad infinitum desse universo, propiciada e provocada pelas mudanças contínuas emanadas das ciências e das técnicas. (...). À medida que fabrica novas realidades, o homem cria novas palavras em um processo incessante. E o léxico vai assumindo dimensões gigantescas sendo praticamente impossível registrá-lo e descrevê-lo por meio de um dicionário. (BIDERMAN, 2006, p. 35)

Há que se considerar que a necessidade de acesso ao significado pelo leitor aqui qualificado não se resume aos termos. Estes talvez lhe sejam mais cognoscíveis pela familiaridade com a área de domínio e pela evidência de raízes latinas em sua construção morfológica. Outro fator impactante a considerar é que a evidente 
e crescente vulgarização de termos de especialidade, resultante das demandas de comunicação entre as esferas científicas e o público leigo, tem tornado menos claras as fronteiras entre a linguagem dos textos e a caracterização de uma terminologia de especialidade. Seja por influência midiática, pela necessidade de discursos mais persuasivos ou pelo acesso facilitado à informação, é fato, que nas mais diversas áreas, deparamo-nos frequentemente com uma linguagem amalgamada, cuja definição do status terminológico requer o suporte de estudos especializados de corpus, com auxílio de extratores automáticos e outros recursos tecnológicos.

\section{Situando a Tradução na abordagem instrumental}

Historicamente, a tradução em salas de aula de língua estrangeira (LE) tem sido rechaçada e considerada como prática perniciosa aos propósitos comunicativos.

A logicidade do método dedutivo de ensino, ancorado nos preceitos analíticos da ciência consolidou-se como o pilar do conhecimento irrefutável pautado na sistematização e regularidade durante o século XIX e início do século XX. No campo do ensino de línguas estrangeiras estão atrelados ao raciocínio dedutivo, por exemplo, o Método Gramática e Tradução com suas características analítico-comparativas e explicações minuciosas dos recortes e unidades discretas que serviam para objetivos específicos de acesso à literatura e não ao uso social da língua.

Vista em retrospecto, as raízes da percepção negativa da tradução estão fincadas em insucessos da metodologia Gramática e Tradução (MGT) quando esta tem suas potencialidades avaliadas para alcançar objetivos linguísticos mais amplos, funcionais e interacionais. Sua inadequação aos propósitos comunicativos lhe justificam as críticas de ensino descontextualizado de palavras, didática enfadonha com desprezo aos usos sociais da língua, atribuição do papel de mero reprodutor ao aluno. (PRATOR \& CELCE-MURCIA, 1979; RICHARDS \& RODGERS, 1986). 
O advento dos métodos naturais de ensino de LE, a reputação dos mecanismos tradutórios aplicados ao ensino sofreu progressivamente grande depreciação ao ponto de surgirem propostas rigidamente dissociativas no âmbito do ensino. Diacronicamente, a chegada da abordagem comunicativa, trazendo em seu cerne os postulados construtivistas e sócio-construtivistas de Piaget e Vygostsky ao cenário da Linguística Aplicada, promoveu a tradução do status de veementemente proibida para pontualmente concebível como estratégia de aprendizagem e apreensão de sentidos. Esta relativa tolerabilidade é legitimada pela supremacia da comunicação das ideias e dos sentidos sobre o ênfase nas fórmulas estruturais e uma atenção mais evidente dispensada à afetividade e ao "compreender e fazer-se compreender" por meios variados e validados.

Nos estudos da tradução a valorização dos sentidos acima das palavras, isto é do significado acima do significante encontra amparo desde Cícero e acompanha os estudos de tradução com exemplificado destaque nos trabalhos de Eco (2007) e Ronái (1987).

A abordagem comunicativa traz como componente axial o conceito de competência comunicativa (CC) que surge como uma reação crítica de Hymes à dicotomia Chomskiana - competência - conhecimento das estruturas sintáticas da língua versus desempenho linguístico - uso da língua (CHOMSKY, 1965 apud HYMES, 1995 , p. 30) vista como reducionista por considerar elementos universais "ideais" e desprezar influências socioculturais que agem sobre eles. Os pressupostos de Hymes desencadeiam extensos e diversificados estudos que resultam na atomização de subcompetências (HYMES, 1966, 1971; CANALE \& SWAIN, 1980; CANALE, 1983; WIDDOWSON, 1989; BACHMAN, 1990).

Sendo a tradução uma atividade essencialmente comunicativa e estando tanto a competência linguística quanto a comunicativa intricadas na competência tradutória, relaciono esse construto ao meu enfoque neste artigo destacando em especial o reconhecimento das subcompetências propostas por Canale (ibdem). Percebo-as como dimensões acolhedoras de mecanismos tradutórios no ensino de LE, seja pelo reconhecimento científico dos benefícios dos pro- 
cessos cognitivos implícitos em dinâmicas de análise contrastiva, em explicações dedutivas de insumos linguísticos complexos da língua estrangeira, ou no reconhecimento das diferenças culturais atitudinais que permitem ao aprendiz fazer comparações e adequações contextuais das regras socioculturais e discursivas no uso da língua em gêneros que são culturalmente definidos, ou ainda, na habilidade do aprendiz em utilizar estratégias compensatórias quando alguma das demais competências deixa lacunas.

Os processos tradutórios cognitivos são mecanismos, por vezes, involuntários e imperceptíveis e nesta condição, inalcançáveis e não manipuláveis pelo docente. Constituem dinâmicas de compreensão que tem como referência a língua materna e ocorrem internamente na busca pela reequilibração sistêmica diante do novo conhecimento - o desenvolvimento da interlíngua. De forma consciente ou inconsciente, a tradução - interiorizada ou didática (HURTADOO-ALBIR, 1998a) - empregada como recurso estratégico do aluno ou recurso didático do docente, tem seus mecanismos presentes e alicerçam os processos de ensino-aprendizagem da língua estrangeira.

A este respeito refere Ross (2000)

\begin{abstract}
A tradução tem especial importância em níveis intermediários e avançados. Nos níveis mais avançados e de conclusão do ensino de língua, traduzir da língua materna (L1) para a língua estrangeira (L2) e no sentido inverso é reconhecidamente a quinta habilidade e a mais importante socialmente pois promove a comunicação e a compreensão entre falantes de diferentes idiomas (ROSS, 2000, pp. 61-66). ${ }^{7}$
\end{abstract}

\footnotetext{
${ }^{7}$ Minha tradução para o original: "Translation holds a special importance at an intermediate and advanced level: in the advanced or final stage of language teaching, translation from L1 to L2 and L2 to L1 is recognized as the fifth skill and the most important social skill since it promotes communication and understanding between strangers" (Ross 2000 p. 61-66).
} 
Pode-se dizer que esta relação tradução - ensino de LE vem sendo ressignificada e se estreitando complacentemente nas décadas mais recentes, à luz das teorias que ampliam sua compreensão dentro das ciências da linguagem, em suas diversificadas formas - seja como produto ou como processo. Pontuo a natureza facilitadora da tradução nos esquemas de leitura e compreensão e, apesar das objeções apontadas ao seu uso nas salas de aula, o contexto de ensino instrumental de LE permanece como seu lugar de existência, legitimada, harmonizada e preservada.

\section{Evidências empíricas na relação entre competências comunicativa, tradutória e conhecimentos terminológicos}

Nesta sessão apresento excertos ilustrativos retirados de textos que utilizei em atividades de consolidação da habilidade leitora em LE nas aulas de Inglês Instrumental dos cursos livres da UFPA nos anos de 2015-2017. A seleção dos textos é prerrogativa dos docentes do curso e devem, em melhor hipótese, atender as áreas de interesse dos integrantes da turma dando ênfase ao gênero textual acadêmico científico. Não há nesta proposta de estruturação curricular um programa pré- estabelecido, ficando este arbítrio condicionado às pesquisas de avaliação de necessidades realizadas pelos docentes no início do curso. A metodologia utilizada para o recorte do corpus de análise observou escolha aleatória de textos que selecionei para práticas no período de 2015 - 2017 seguidos de reflexões atinentes aos aspectos linguísticos formais, tradutórios e terminológicos .

I. Texto: The Net Generation in Japan: a survey of internet behavious of students aged 13-21. By Keith Tanton ${ }^{8}$

${ }^{8}$ http://www.tewtjournal.org área(s) do conhecimento: Tecnologia / Educação / Ensino de LE 
(a) While distance education has been using technology to deliver courses to students in non-traditional settings, recent innovations such as blended learning bring technology directly into the classroom for purposes other than ICT instruction

(b) Many forms of technology are being introduced into educational environments: smart boards, Web 2.0 technologies like blogs, Facebook and YouTube, Virtual Learning Environments such as Moodle and Blackboard, and mobile apps for learning that are available on cell phones or other mobile Internetconnected devices

(c) Social media like blogs can be used as a constructivist learning tool, which can encourage students to participate in the making of meaning and knowledge through content creation activities, critical feedback on others' content, and critical reflection on their learning (Lee, 2011).

II. Texto: Corruption in Latin America: An empirical overview. By Stephen D. Morris 9

(a) Since the late nineties, and amid (...) growing disillusionment over the sluggish advances of democratic and neoliberal economic reforms, (...)

(b) (...) corruption tends to be higher in countries at lower levels of economic and human development, (...), ethno-linguistic factionalism, the lack of judicial independence and a free press, low civil service wages, (...)

(c) (...) corruption lowers the rate of economic growth and investment, distorts public spending by diverting funds to sectors where

${ }^{9} \mathrm{http}: / /$ citeseerx.ist.psu.edu/viewdoc/download?doi $=10.1 .1 .503 .5018 \& \mathrm{rep}=$ rep $1 \&$ type $=$ pdf área(s) do conhecimento: Ciências Sociais.

Cad. Trad., Florianópolis, v. 38, no 3, p. 399-425, set-dez, 2018 
the collection of bribes is easier (...), weakens programs designed to help the poor and reduce inequality, reduces government revenue through tax evasion and improper tax exceptions, lowers foreign aid and influences the structure of trading partners.

III. Texto: Groundwater arsenic contamination in Bangladesh: causes, effects and remediation. By Safiuddin; Karim ${ }^{10}$

(a) This layer is rich in arseno-pyrite, pyrite, iron sulfate, and iron oxide as revealed by the geological investigation. (...), although arsenic is occurring in the alluvial sediments (...).

(b) Excessive groundwater extraction may be the vital reason for creating a zone of aeration in clayey and peaty sediments containing arseno-pyrite.

(c) The data (...) reveal that a large number of populations in Bangladesh are suffering from melanosis, leuco-melanosis, keratosis, hyperkeratosis, dorsum, non-petting oedema, gangrene and skin cancer.

Os itens em destaque permitem evidenciar que os desafios requerem tanto a competência comunicativa em LE - em suas dimensões gramatical e discursiva (CANALE, 1983) quanto conhecimentos terminológicos que possibilitam acesso ao termo. É redundante mencionar o indispensável suporte da competência tradutória, dado que esta abrange as subcompetências bilíngue e estratégica entre outras (PACTE, 2003), e enreda portanto, a totalidade do processo.

$\mathrm{O}$ quadro 03 sintetiza ocorrências que compatibilizam os saberes terminológico e linguístico em excertos selecionados aleatoriamente. Elencamos as categorias empréstimos / termos vulga-

${ }^{10}$ http://eng-consult.com/pub/ArsenicIEB.pdf área(s) do conhecimento: saúde e meio ambiente.

Cad. Trad., Florianópolis, v. 38, no 3, p. 399-425, set-dez, 2018 
rizados e cognatos, termos de especialidade e itens do domínio linguístico-discursivo no intuito de exemplificar como estes elementos se mesclam exigindo as habilidades referidas. Aponto nos fragmentos, alguns itens suficientemente ilustrativos. Sob a categoria empréstimos/termos vulgarizados/cognatos exemplifico unidades que indicam influências de contato interlinguístico ou estruturas morfológicas próximas que favorecem a compreensão do termo em língua estrangeira e, portanto, a localização de um correspondente em língua materna. Em alguns casos, como em áreas mais recentes da ciência, campos que evoluem aceleradamente, a exemplo da tecnologia da informação, o empréstimo de termos em LE é algo comum por parte das comunidades linguísticas que são mais receptoras do que produtoras de dado conhecimento. Por outro lado, o processo de vulgarização de termos decorrente de fenômenos de globalização e tradução simplificada do conhecimento especializado ao público não especialista (BOTTA, 2013) pode gerar uma compreensão distorcida do termo de especialidade. Neste sentido, a competência do especialista é essencial para acuidade dos sentidos. Sob a categoria termos de especialidade listamos itens lexicais e unidades fraseológicas que preservam estreita relação com um domínio especifico. Em itens do domínio linguístico-discursivo ressaltamos algumas estruturas sintáticas para cuja compreensão o conhecimento do sistema de funcionamento de regras da LE se faz necessário. São exemplos de situações em que o uso do dicionário é insuficiente. Envolve, marcadores discursivos, conectores que criam relações de dependência, estruturas verbais complexas, voz passiva, emprego de pronomes relativos, modais e até mesmo algumas expressões adverbiais de tempo. 
Quadro 03: Categorização de itens lexicais interpostos no texto de especialidade

\begin{tabular}{|c|c|c|c|}
\hline $\begin{array}{l}\text { Texto/ } \\
\text { excerto }\end{array}$ & $\begin{array}{l}\text { Empréstimos/ } \\
\text { Termos } \\
\text { vulgarizados/ } \\
\text { cognatos }\end{array}$ & Termos de especialidade & $\begin{array}{l}\text { Itens do domínio } \\
\text { linguístico-discursivo }\end{array}$ \\
\hline \multirow[t]{4}{*}{$\mathrm{I} / \mathrm{a}$} & & \multirow[t]{3}{*}{ Blended learning } & while \\
\hline & & & Has been using \\
\hline & & & \multirow{2}{*}{$\begin{array}{l}\text { For purposes other } \\
\text { than }\end{array}$} \\
\hline & & ICT Instructions & \\
\hline \multirow[t]{4}{*}{$\mathrm{I} / \mathrm{b}$} & Blogs & smart boards, & \multirow[t]{4}{*}{ are being introduced } \\
\hline & YouTube & Web 2.0 technologies & \\
\hline & Facebook & Virtual Learning & \\
\hline & mobile apps & $\begin{array}{l}\text { Environments } \\
\text { Moodle }\end{array}$ & \\
\hline \multirow[t]{2}{*}{$\mathrm{I} / \mathrm{c}$} & \multirow[t]{2}{*}{ Social media } & constructivist learning tool & can be used \\
\hline & & Content creation activities & which can encourage \\
\hline II / a & & neoliberal economic reforms & $\begin{array}{l}\text { Since the late } \\
\text { nineties, and amid }\end{array}$ \\
\hline II $/ \mathrm{b}$ & & ethno-linguistic factionalism & \\
\hline \multirow[t]{2}{*}{ II / c } & & tax exceptions & by diverting \\
\hline & & Trading partners & $\begin{array}{l}\text { Where (of bribes is } \\
\text { easier) }\end{array}$ \\
\hline \multirow[t]{4}{*}{ III / a } & & arseno-pyrite, and & \\
\hline & & iron sulfate, & \\
\hline & & iron oxide & \\
\hline & & Aluvial sediments & \\
\hline \multirow[t]{2}{*}{ III / b } & & Zone of aeration & \\
\hline & & Clayey, peaty sediments & \\
\hline \multirow[t]{6}{*}{ III / c } & gangrene & Melanosis & \\
\hline & \multirow[t]{5}{*}{ skin cancer } & leuco-melanosis & \\
\hline & & Keratosis & \\
\hline & & Hyperkeratosis & \\
\hline & & Dorsum & \\
\hline & & non-petting oedema & \\
\hline
\end{tabular}

Fonte: elaborado pela autora. 


\section{Conclusão}

O ensino de ESP realizado em cenário de aprendizagem de cursos livres de língua estrangeira, com as especificidades descritas neste artigo, requer a percepção docente para uma diversidade de aspectos, entre os quais se destacam os relacionados aos interesses imediatos dos discentes, ao gênero em foco e às estratégias didáticas que os empoderem, permitindo-lhes compartilhar a posição de expert do conhecimento especializado, destacadamente quando os fatores terminológicos assumem papel determinante na construção de sentidos a partir informações contidas no texto. Quem escreve o texto de especialidade, escreve para uma comunidade que compartilha um acervo de informações e conhecimentos específicos, daí advém o entendimento de que o conceito subjacente ao termo é de penetrabilidade esperada por este leitor tipificado, ainda que em língua estrangeira. Ao docente, em contrapartida, cabe implementar mecanismos para substanciar da atividade leitora com o aporte da competência bilíngue - como componente da competência tradutória e da consciência linguageira - language awareness via metalinguagem. Atribuo relevância aos aspectos morfológicos e sintáticos, aos mecanismos de articulação entre ideias e componentes das frases, às estratégias de abordagem textual, onde se incluem também a otimização do tempo, as buscas por soluções de tradução adequadas ao contexto do texto e o uso racional dos instrumentos terminográficos e tecnológicos de apoio.

Nas salas de língua inglesa instrumental, no cenário aqui explorado, vejo potencializados os caminhos colaborativos que são trilhados na mediação do processo de ensino-aprendizagem em sua perspectiva construtivista, a utilização de recursos variados de pesquisa, o ensino de estratégias tradutórias e interpretativas e o reconhecimento da expertise compartilhada. A aglutinação destes componentes sinalizam oportunidades válidas de desenvolvimento recíproco dos agentes envolvidos - docentes e discentes - no que se refere aos modos de ensinar e aprender e à alternância de papeis, com implicações na tessitura dos currículos de curso de ESP. 


\section{Referências}

ARAÚJO, Marcus de Souza. Inglês para Fins Específicos: o desenho de um curso a partir da análise de necessidades. Revista Intercâmbio, v. XXX, [S.L], p. 5179, 2015.

BACHMAN, Lyle. Fundamental Considerations in language Testing, Oxford: Oxford University Press, 1990.

BELCHER, Diane. English for specific purposes: Teaching to perceived needs and imagined futures in worlds of work, study, and everyday life. TESOL Quarterly, 40, [S.L], 133-156, 2006.

. What ESP is and can be: An introduction. In: (Ed.), English

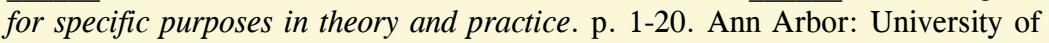
Michigan Press, 2009.

BELL, Timothy. Extensive Reading: Why? And How? Internet TESL Journal, v. IV, n. 12, [S.L], Dec. 1998. Disponível em http://iteslj.org/Articles/BellReading.html acesso em 08 de outubro 2017.

BHATIA, Vijay Kumar. Analysing genre: Language use in professional settings. London: Longman, 1993.

BIDERMAN, Maria Teresa Camargo. O conhecimento, a terminologia e o dicionário, Cienc. Cult. v. 58 n. 2. São Paulo Apr./June 2006. Disponível em: http://cienciaecultura.bvs.br/pdf/cic/v58n2/a14v58n2.pdf. Acesso em 01/10/2017.

BRASIL. Secretaria de Educação Fundamental. Parâmetros curriculares nacionais: terceiro e quarto ciclos do ensino fundamental. Língua portuguesa. Brasília: MEC/SEF, 1998.

BOTTA, Mariana Giacomini. Comportamento dos termos do meio ambiente em textos de vulgarização. TradTerm, São Paulo, v. 22, Dezembro/2013, p. 191-216 
CANALE, Michael. From communicative competence to communicative language pedagogy. In: RICHARDS, J.C.; SCHMIDT, R.W. (Eds.) Language and Communication, Londres: Longman. 1983.

; SWAIN, M. 1980. Theoretical Bases of Communicative Approaches to Second Language teaching and testing. Applied Linguistics, v. 1, [S.L], 1980.

CELANI, M. A. A. Considerações sobre a pesquisa: a necessidade e eficiência do ensino de inglês instrumental em Universidades brasileiras. The ESPecialist, 6: 2-9, [S.L], 1983.

De AQUINO, Carlos Tasso Eira. Como Aprender: andragogia e as habilidades de aprendizagem. São Paulo: Pearson, $1^{\text {a }}$ ed., 2007.

DUDLEY- EVANS, Tony \& St. JOHN, Maggie Jo. Developments in English for specific purposes: A multi-disciplinary approach. Cambridge, UK: Cambridge University Press, 1998.

ECO, Umberto. Quase a Mesma Coisa. Tradução de Eliana Aguiar. São Paulo: Record, 2007.

FAULSTICH, Enilde Leite de Jesus; ABREU, Sabrina Pereira. Linguística aplicada à Terminologia e à Lexicografia. Porto Alegre: UFRGS, 2003.

GAVIOLI, Laura. Exploring corpora for ESP learning. Amsterdam: John Benjamins, 2005.

HAMP-LYONS, Liz. English for Academic Purposes. In: CARTER, Ronald; NUNAN, David (Eds.), The Cambridge guide to Teaching English to Speakers of Other Languages. Cambridge: Cambridge University Press, p. 126-130, 2001.

HASAN, Ruqaiya. What's going on: a dynamic view of context in language. In: BUTT, David; CLORAN, Carmel; WILLIAM, Lycan, (Eds.) Ways of Saying: Ways of Meaning. London: Cassel, p. 37-50, 1996b.

HENSCHKE, John. Perspectives on International Adult Education. Adult Learning, v. 16, n. 1;2, [S.L], 2008. 
HURTADO-ALBIR, Amparo. La traducción en la enseñanza comunicativa. Cable: revista de didáctica del español como lengua extranjera, Madrid, p. 42-45 1988a.

HUTCHINSON, Tom \& WATERS, Alan. English for specific purposes: A learning-centred approach. Cambridge, UK: Cambridge University Press, 1987.

HYLAND, K. Specificity revisited: How far should we go now? English for Specific Purposes, v. 21, n. 4, [S.L], p. 385-395, 2002.

Press, 2004.

. Genre and second language writing. Ann Arbor: University of Michigan

. English for academic purposes: An advanced resource book. London: Routledge, 2006.

HYMES, Dell Hathaway. Two types of Linguistic Relativity. In: BRIGHT, William Sociolinguistics. The Hague: Movton, p.114-158, 1966. . Acerca de la Competencia Comunicativa. In: LLOBERA, Miquel. et al. Competencia comunicativa. Documentos básicos en la enseñanza de lenguas extranjeras. Madrid: Edelsa, 1995.

. On Communicative Competence, Philadelphia: University of Pennsylvania Press, 1971.

JOHNS, Ann.; DUDLEY-EVANS, Tony. English for specific purposes: International in scope, specific in purpose. TESOL Quarterly, 25, [S.L], p. 297314, 1991.

KIRALY, Donald. A Social Constructivist Approach to Translator Education; Empowerment from Theory to Practice, London; New York: Routledge, 2000.

KNOWLES, Malcolm Shepherd. The modern practice of adult education: From pedagogy to andragogy. Englewood Cliffs: Prentice Hall -Cambridge, 1980. 
PACTE. Building a translation competence model. In: ALVES, Fabio. (Ed.). Triangulating Translation: Perspectives in process oriented research. Amsterdam /Philadelphia: John Benjamins, p. 43-66, 2003.

. Investigating Translation Competence: Conceptual and Methodological Issues. Meta: jounal des traducteurs, v. 50, n. 2, p. 609-619, Montreal, 2005.

PALTRIDGE, Brian. Genre and English for specific purposes. In: PALTRIDGE, Brian; STARFIELD, Sue. (Eds). The handbook of English for specific purposes. Boston: Wiley-Blackwell, 2013.

PRATOR, Clifford; CELCE-MURCIA, Marianne. An Outline of Language Teaching Approaches. In: CELCE-MURCIA, Marianne; McINTOSH, Lois (Ed.), Teaching English as a Second or Foreign Language. Newbury House, 1979.

RAMOS, Rosinda C.G. A história da abordagem instrumental na PUCSP. In: CELANI,M.A.A., RAMOS, R.C.G., FREIRE, M.M. (Orgs.). A abordagem instrumental no Brasil: um projeto, seus percursos e seus desdobramentos. Campinas:Pontes Editores, 2005.

RICHARDS, Jack; RODGERS, Theordore. Approaches and Methods in Language Teaching. Cambridge: University Press, 1986.

RÓNAI, Paulo. Escola de Tradutores. $6^{\text {a }}$ ed. Rio de Janeiro: Nova Fronteira, p.13, 1987.

ROSS, Nigel. Interference and Intervention: Using Translation in the EFL Classroom. Modern English Teacher, v. 3. n. 9, [S.L], p. 61-66, 2000.

SCHMIDT, Richard. The role of consciousness in second language learning. Applied Linguistics, v. 11, [S.L], p. 129-158, 1990.

STREVENS, Peter. New Orientations in the Teaching of English. Oxford: Oxford University Press, 1977.

SWALES, John Malcolm. Genre analysis in English in academic and research settings. Cambridge: Cambridge University Press, 1990. 
WIDDOWSON, Henry. Knowledge of Language and Ability for use. Applied Linguistics v. 10(2), [S.L], 1989.

Recebido em: 19/04/2018

Aceito em: 05/06/2018

Publicado em setembro de 2018

Silvia Helena Benchimol Barros. E-mail: silviabenchimol@hotmail.com ORCID: http://orcid.org/0000-0002-7177-1502 